\title{
Influence of climate changes on filling loss dynamics (a case study from the Republic of Bashkortostan)
}

\author{
Alexey Elizaryev ${ }^{1,3^{*}}$, Dmitry Tarakanov ${ }^{1}$, Antonia Longobardi ${ }^{2}$, Denis Tarakanov $^{1}$, Elina \\ Nasyrova $^{1}$, Sergey Aksenov ${ }^{1}$, and Elena Elizareva ${ }^{1}$ \\ ${ }^{1}$ Ufa State Aviation Technical University, K. Marx Street, 12, Ufa, 450000, Russia \\ ${ }^{2}$ University of Salerno, Via Giovanni Paolo II, 132 - 84084, Fisciano (SA), Italy \\ ${ }^{3}$ Russian Academy of Sciences, Gubkina Street, 3, Moscow, 119333, Russia
}

\begin{abstract}
On the example of Republic of Bashkortostan, the study of the influence of climate changes on the dynamics of filling loss (big breathing) was carried out. The analysis of the homogeneity of the time series of the average annual air temperature allowed us to obtain periods in which the values of the average annual temperatures are unchanged. For the found periods, the values of losses from big breathing are calculated. The influence of climate change is shown by comparing the results of calculations of the values of big breathing in the first and last homogeneous time periods. Similarly, the influence of climate change on the seasonal values of big breathing in the period from 1950 to 2018 is shown. The results of the study showed that climate changes lead to an increase in the volume of filling loss throughout the Republic of Bashkortostan (by more than 3\%). Seasonal losses are also increasing. The maximum growth is observed in winter. Changes in climate conditions lead to an increase in the risk of explosive situations due to filling loss, and an increase in the level of environmental pollution.
\end{abstract}

\section{Introduction}

Big breathing occur when the tank is filled/emptied. They are the release of a vapor-air mixture into the environment. The release leads to a permanent deterioration of the environmental condition of the territory of oil product storage facilities and to the occurrence of explosive and fire-hazardous situations when the ignition source appears [1]. The main losses of oil products fall on storage in tanks (about $70 \%$ of the total amount). Big breathing account for the main share of losses (more than 50\%). There are many studies devoted to the problem of big breaths [1-6]. Bahadori in his work [2] suggests using two methods for predicting the number of losses when filling reservoirs. Other researchers [3] focus on creating and researching a model that will estimate the emissions of steam-air mixture from reservoirs.

\footnotetext{
*Corresponding author: elizariev@ mail.ru
} 
Work [6] shows a significant influence of climatic conditions on the volume of filling loss (big breathing). The daily temperature difference and atmospheric pressure change the volume of the vapor phase. This leads to a change in the amount of loss from big breathing.

The main objective of the article is to study the influence of climate changes at filling loss dynamics (on example of the Republic of Bashkortostan).

\section{Materials and methods}

The Republic of Bashkortostan is taken as the object of research. It is located in a temperate climate zone. The climate of the Republic (with an area of $142.947 \mathrm{~km}^{2}$ ) is characterized by low humidity, warm summers and harsh winters. The average annual air temperature in the Central and South-Western regions is $2^{\circ} \mathrm{C}, 3^{\circ} \mathrm{C}$. The average annual air temperature in Gorny and Vostochny is $0^{\circ} \mathrm{C}, 1^{\circ} \mathrm{C}$. This difference in temperature is explained by the variety of terrain and the presence of the Ural mountains. During the study, a vertical steel tank with a capacity of $5,000 \mathrm{~m}^{3}$ was selected as the object for calculations. Weather stations located in the districts of Yanaul, Duvan, Ufa, and Zilair are considered. During the study, more than 3,000 thousand values were processed.

To understand the influence of climate changes on filling loss dynamics, it is necessary to identify periods with the same values of average annual temperatures. The analysis of the homogeneity of time series of air temperature is carried out in the following sequence: 1) identification of periods of violation of homogeneity; 2) checking for homogeneity using parametric (Fisher (F), Student (St)) and nonparametric (Wilcoxon-Mann-Whitney (U)) criteria.

Comparing the results obtained for deleting time periods with the results of similar works by other authors will allow you to check the accuracy of the results 8 .

For a detailed study the influence of climate changes at filling loss dynamics, it is necessary to identify periods within which the average annual seasonal temperatures are unchanged (for Ufa). It is necessary to perform an analysis of the homogeneity of the time series of the average annual seasonal temperature (the analysis is carried out similarly) 9.

\section{Results and discussion}

Using graphical analysis, straight sections of integral curves are determined. They are defined as homogeneous. For an example, see Figure 1 shows the integral curves of average annual air temperature values $\left(\sum T\right)$ in the Central (Ufa) and Northern (Yanaul) districts.

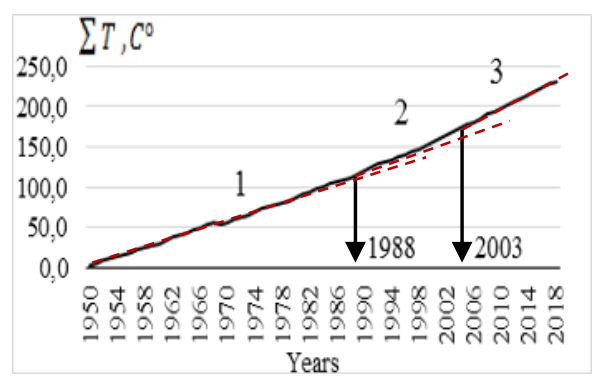

a) Ufa.

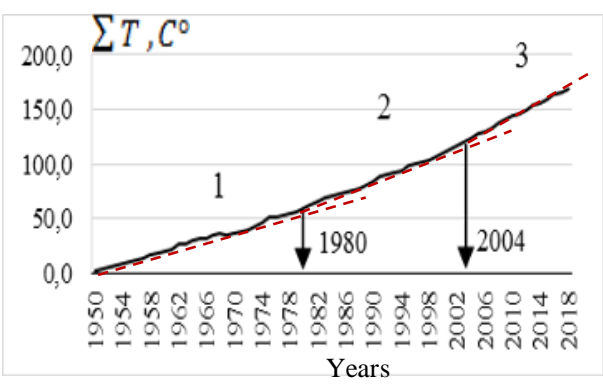

b) Yanaul.

Fig. 1. Change in the incoming sum of average annual air temperature values $\left(\sum T\right)$ in Ufa (a) and Yanaul (b). 
Homogeneity was checked using parametric and nonparametric criteria. The violation of the uniformity of the series of average annual temperature values was confirmed. The results of the analysis of the homogeneity of the time series of the average annual temperature are shown in Table. 1.

Table 1. Results of estimation of uniformity of time series of average annual air temperature values at the considered weather stations.

\begin{tabular}{|c|c|c|}
\hline \multirow{2}{*}{$\begin{array}{c}\text { Observation } \\
\text { point }\end{array}$} & \multicolumn{2}{|c|}{ Average annual air temperature $T,{ }^{\circ} \mathrm{C}$} \\
\cline { 2 - 3 } Yanaul & Statistically homogeneous period & Average \\
& $1950-1979$ & 1.9 \\
& $1980-2003$ & 2.6 \\
& $2004-2018$ & 3.2 \\
\hline \multirow{3}{*}{ Duvan } & $1950-1979$ & 1.3 \\
& $1980-1983$ & 3.2 \\
& $1984-2006$ & 2.3 \\
Ufa & $2007-2018$ & 2.9 \\
\hline \multirow{3}{*}{ Zilair } & $1950-1987$ & 2.8 \\
& $1988-2002$ & 3.7 \\
& $2003-2018$ & 4.3 \\
\hline
\end{tabular}

The obtained results of dividing time series into periods (within which long-term temperature values are unchanged) were compared with the works of other authors 8 . The results of the comparison revealed no significant differences (no more than 3 years)

According to the data from Table 1, there is an increase in the average annual temperature at each observation point (comparing the values of the first and last homogeneous time periods). The comparison results showed an increase in the average annual temperature by 2018 in the North (Yanaul) of the Republic of Bashkortostan of $1.3^{\circ} \mathrm{C}(1.7$ times $)$, in the North-East (Duvan) $-1.6^{\circ} \mathrm{C}$ (2.2 times), in the Central part (Ufa) $1.4^{\circ} \mathrm{C}(1.5$ times $)$, in the southern part (Zilair) $-1.6^{\circ} \mathrm{C}(2$ times $)$.

Using the graphical analysis of the determined straight-line plots of the integral curves.

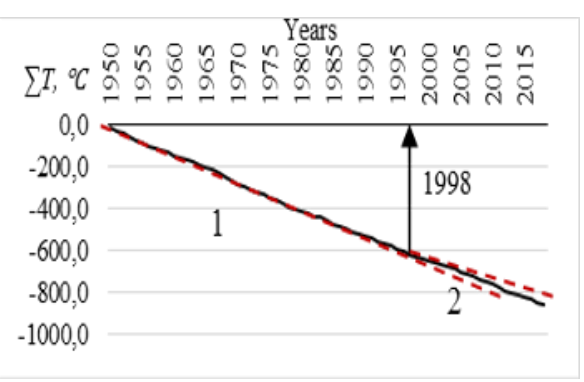

a) Winter season

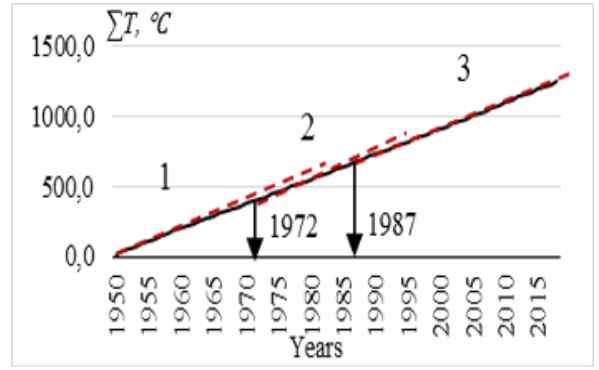

b) Summer season

Fig. 2. Change in the incoming sum of the average annual seasonal air temperature values in Ufa $\left(\sum T\right)$ in the winter $(a)$ and summer $(b)$ periods.

For Figure 2 shows the integral curves of the average seasonal values of air temperature $(\Sigma T)$ for the Central part of the Republic (summer and winter). A test of homogeneity for parametric and non-parametric criteria confirmed the validity of the graphic analysis. The 
results of the analysis of the homogeneity of the time series of average seasonal air temperature are given in Table. 2.

Table 2. Results of estimation of homogeneity of time series of average annual seasonal values of air temperature in the Central part of the Republic of Bashkortostan (Ufa).

\begin{tabular}{|c|c|c|}
\hline \multirow{2}{*}{ Period } & \multicolumn{2}{|c|}{ Average annual seasonal value of air temperature $T,{ }^{\circ} \mathrm{C}$} \\
\cline { 2 - 3 } Winter & Statistically homogeneous period & Average \\
\hline \multirow{3}{*}{ Spring } & $1950-1997$ & -12.9 \\
& $1997-2018$ & -11.3 \\
\hline \multirow{3}{*}{ Summer } & $1950-1972$ & 3.4 \\
& $1973-1980$ & 5 \\
& $1981-1988$ & 3.5 \\
& $1989-2018$ & 4.9 \\
\hline \multirow{3}{*}{ Autumn } & $1950-1971$ & 17.9 \\
& $1972-1986$ & 17.6 \\
& $1987-2018$ & 18.5 \\
\hline & $1950-1961$ & 2.4 \\
& $1962-1974$ & 3.7 \\
& $1975-1999$ & 3.1 \\
& $2000-2013$ & 5.1 \\
\hline
\end{tabular}

The impact of climate change is expressed in changes in the volume of big breathing between 1950 and 2018. Using the results obtained for the temperature regime, the values of big breathing for the considered regions of the Republic of Bashkortostan are calculated (Figure 3).

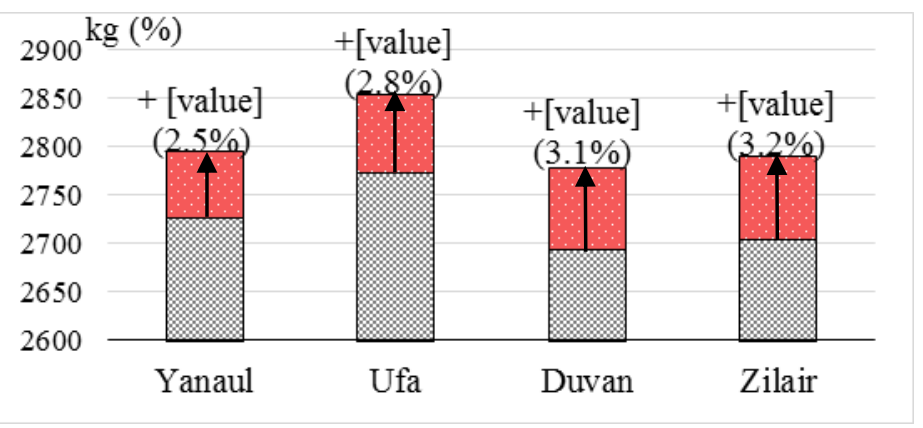

Fig. 3. Changes in the magnitude of big breathing in the regions under consideration in the Republic of Bashkortostan from 1950 to 2018.

Figure 3 showed the largest increase in fumes from filling loss. It is observed in the southern part of the Republic (86 kg-3.2\%). In each area under consideration, due to changes in climate conditions, there was an increase in the magnitude of big breathing. The increase in the volume of vapors of petroleum products is more than $70 \mathrm{~kg}$ per breath. If the results are translated into annual values, the increase in losses from large breaths will be more than $25,200 \mathrm{~kg}$.

The analysis of seasonal changes in filling breathing over the same period shows in more detail the impact of climate changes on the dynamics of big breaths of the population. Seasonal changes in the magnitude of large breaths under climate change conditions are shown in Figure 4. 


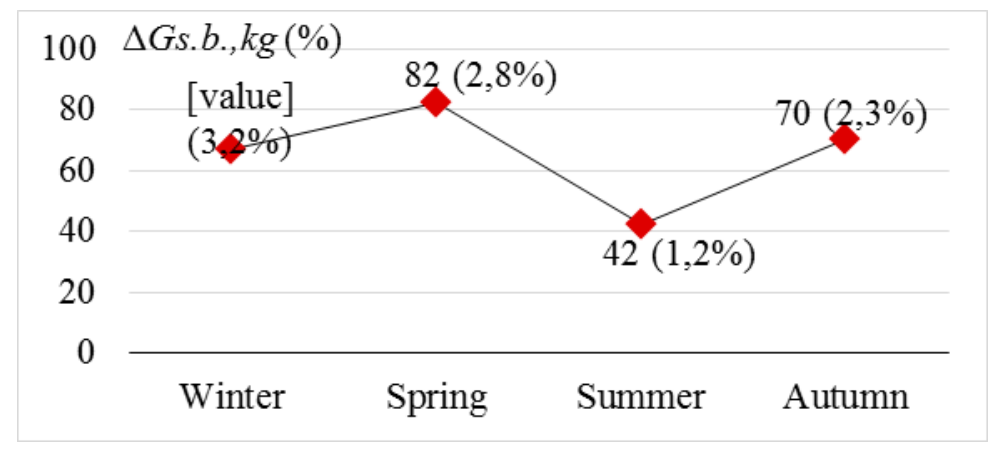

Fig. 4. Change in the magnitude of big breathing under climate change conditions from 1950 to 2018.

Analysis of Figure 4 showed an increase in seasonal volumes of big breathing (more than $40 \mathrm{~kg}$ ). The greatest growth is observed in the winter period (more than $3 \%$ ). With the largest amount of losses in the summer season, big breathing have the smallest change, which indicates that there is no connection between these values.

\section{Conclusion}

The study analyzed the homogeneity of time series of air temperature according to observations from 4 weather stations (Yanaul, Ufa, Zilair, Duvan). During the analysis, more than 3,000 values for the temperature regime of the Republic of Bashkortostan were processed. The results of the analysis for the homogeneity of time series allowed us to determine periods with constant average annual temperature values. Based on the results of the air temperature, the calculation of filling loss was performed. The calculation is performed for the considered areas in each time period. For Ufa, the calculation of seasonal losses of oil products in the same period was performed. The results of calculations showed the influence of climate changes on the dynamics of big breathing. It was determined that under the influence of climate changes, the volume of big breaths in the entire territory of the Republic of Bashkortostan increased by more than $2.5 \%$. The highest change in the seasonal value of losses is observed in the winter period (more than $3 \%$ ). In General, changes in climate conditions lead to an increase in the probability of occurrence of explosive situations from filling loss, an increase in economic losses, and an increase in the level of environmental pollution.

The presented research was financially supported by the Russian Science Foundation (grant no. 1777-30006).

\section{References}

1. A. Elizaryev, G. Maniakova, R. Gabdulkhakov, et al., Int. J. of Eng. and Tech., 7, 2427 (2018) DOI: 10.14419/ijet.v7i2.23.11876

2. A. Bahadori, A. Baghban, M. Bahadori, et al., Petroleum Science and Technology, 34 (2), 145-152 (2016) DOI: 10.1080/10916466.2015.1122631

3. Y. Liang, DOI: 10.3969/j.issn.1000-1158.2018.06.20

4. V. Pshenin, N. Zaripova, and K. Zaynetdinov, Petroleum Science and Technology, 37(24), 2435- 440 (2019) DOI: 10.1080/10916466.2019.1655442 
5. V.F. Danilov, R.H. Muhutdinov, V.Y. Shurygin, and R.M. Timerbaev, International Journal of Applied Engineering Research, 10(24), 44900-44905 (2015)

6. D. Littlejohn, D. Lucas, Journal of the Air \& Waste Management Association, 53(3), 360-365 (2003) DOI: 10.1080/10473289.2003.10466158

7. I. Afanasev, T. Volkova, and A. Elizaryev, Russian Federation WSEAS transactions on environment and development, 10(1), 405-416 (2014)

8. A.V. Golovina, Evaluation of the modern variability of the stock R. Belay' (Republic of Bashkortostan) under the influence of natural and anthropogenic factors (Abstract of candidate dissertation, Kazan, 2012)

9. V.M. Gaponov, A.N. Elizaryev, et al., IOP Conference Series: Earth and Environmental Science, 350 (1), art. no. 012003 (2019) DOI: 10.1088/17551315/350/1/012003

10. H. Schmidli, Weihs, The Chem. Engin. J. and the Bio. Eng. J., 55, 61-68. 